\title{
Fibrillin-1 expression in normal and fibrotic rat liver and in cultured hepatic fibroblastic cells: modulation by mechanical stress and role in cell adhesion
}

\author{
Dionne Lorena ${ }^{1,2}$, Ian A Darby ${ }^{3}$, Dieter P Reinhardt ${ }^{4}$, Vincent Sapin ${ }^{5}$, Jean Rosenbaum ${ }^{1}$ and \\ Alexis Desmoulière ${ }^{1}$ \\ ${ }^{1}$ Groupe de Recherches pour l'Etude du Foie, INSERM E0362, and Institut Fédératif de Recherche 66, \\ Pathologies Infectieuses et Cancers, Université Victor Segalen Bordeaux 2, Bordeaux, France; ${ }^{2}$ Departamento \\ de Histologia e Embriologia, Universidade do Estado do Rio de Janeiro, Rio de Janeiro, Brazil; ${ }^{3}$ Wound \\ Healing and Microvascular Biology Group, School of Medical Sciences, RMIT University, Victoria, Australia; \\ ${ }^{4}$ Institut fur Medizinische Molekularbiologie, Lubeck, Universitat zu Lubeck, Germany and ${ }^{5}$ INSERM U384, \\ UFR Médecine, Clermont-Ferrand, France
}

\begin{abstract}
Fibrillin-1, together with elastin, is the main component of elastic fibers found throughout the extracellular space and responsible for the biomechanical properties of most tissues and organs. In this work, fibrillin-1 expression and modulation were explored in experimental rat liver fibrosis and in vitro; furthermore, the role of fibrillin-1 fragments on cell adhesion was analyzed. Fibrosis was induced by subjecting rats to common bile duct ligation for $72 \mathrm{~h}$ and 7 days or carbon tetrachloride $\left(\mathrm{CCl}_{4}\right)$ treatment for 2 and 6 weeks. Immunohistochemistry showed that, after bile duct ligation, fibrillin-1, elastin, and $\alpha$-smooth muscle actin colocalized in the developing portal connective tissue. In $\mathrm{CCl}_{4}$-treated animals, a similar colocalization was observed in septa; however, elastin deposition was not observed around activated $\alpha$-smooth muscle actin-positive stellate cells of the parenchyma. Treatment with the profibrogenic mediator transforming growth factor- $\beta 1$ (TGF- $\beta 1$ ) greatly increased the fibrillin-1 expression of cultured liver fibroblasts. The level of fibrillin-1 expression was significantly higher in cells grown in restrained (stressed) collagen lattices compared with those grown in unrestrained collagen lattices. Cell adhesion on the C-terminal fragment of fibrillin-1 containing the RGD sequence $(\mathrm{rF} 6 \mathrm{H})$ slightly increased (between 0.3 and $2.5 \mu \mathrm{g} / \mathrm{ml}$ ) and decreased at higher concentrations, while adhesion on the N-terminal fragment of fibrillin-1 ( $\mathrm{rF} 16)$ was dose-dependently decreased. In addition, the rF16 fragment decreased cell adhesion to fibronectin. In conclusion, our study illustrates the important deposition of fibrillin-1 that occurs in two mechanistically distinct settings of liver fibrogenesis. Furthermore, the induction of fibrillin- 1 expression by TGF- $\beta 1$ and mechanical stress, and the antiadhesive properties of fibrillin- 1 fragments suggest important implications for physiological and pathological fibrillin-1 catabolism during tissue remodeling.

Laboratory Investigation (2004) 84, 203-212, advance online publication, 8 December 2003; doi:10.1038/labinvest.3700023
\end{abstract}

Keywords: microfibril; fibrillin; liver fibrosis; myofibroblast; collagen lattice; adhesion

Many types of extracellular matrix components are present in the liver including different fibrillar (types I, III, V, and VI) and nonfibrillar (types IV and XVIII) collagens, non collagenic glycoproteins such as fibronectins, laminins, and osteonectin/

Correspondence: Dr A Desmoulière, GREF, INSERM E0362, Université Victor Segalen Bordeaux 2, 146 rue Léo Saignat, 33076 Bordeaux, France.

E-mail: Alexix.Desmouliere@gref.u-bordeaux2.fr

Received 16 July 2003; revised 9 October 2003; accepted 17

October 2003; published online 8 December 2003
SPARC, and proteoglycans (eg syndecans, glypican). In normal liver, low amounts of extracellular matrix are observed mainly located around centrilobular veins, along sinusoids in Disse space and in portal zones. In liver fibrosis, an extensive deposition of extracellular matrix can be observed where type I collagen becomes pre-eminent.

While it is well established that the hepatic stellate cells (HSC) play an important role in extracellular matrix deposition and liver fibrogenesis, ${ }^{1,2}$ other fibroblastic cells can also be involved in the development of liver fibrosis. Specifically, it 
has been shown that portal fibroblasts are involved in the fibrotic lesions that develop around portal areas following bile duct ligation in the rat. ${ }^{3-5}$ Indeed, after bile duct ligation, a marked and transient proliferation of bile duct epithelial cells is observed, associated with proliferation of portal periductular fibroblasts, which rapidly acquire a myofibroblastic $\alpha$-smooth muscle actin expressing phenotype. $^{3}$ Identification of differentially expressed markers has added further evidence for the heterogeneity of liver fibrogenic cells. ${ }^{6-9}$

We have previously described the presence of fibrillin-1 in normal and pathological human liver. ${ }^{10}$ Fibrillin-rich microfibrils are important structural elements widely expressed in connective tissues. Depending on the location, microfibrils, and microfibril-associated glycoproteins may be associated with an amorphous elastin core to form elastic fibers. In normal human liver, fibrillin-1 and elastin colocalized in the vessel walls and in the portal tract connective tissue; fibrillin-1 alone was detected along sinusoids. Sinusoids in cirrhotic nodules and fibrotic septa surrounding the nodules were usually rich in fibrillin-1. In hepatocellular carcinomas, fibrillin-1 was present between tumoral hepatocytes and in the stromal reaction around the tumors. We have also observed that fibrillin-1 expression is decreased around bile ducts in children with several types of biliary diseases, suggesting that the mechanical properties of fibrillin-1 may be involved in the regulation of bile flow. ${ }^{11}$ Moreover, fibrillin may act as a classical adhesion protein as it contains an Arg-Gly-Asp (RGD) motif that interacts with the integrin $\alpha \mathrm{V} \beta 3 .{ }^{12,13}$ However, the roles played by microfibrils remain to be elucidated even if new approaches have begun to reveal important insights into their biochemical properties, particularly, their extensible properties and their relevance in dynamic connective tissues with long-range elasticity. ${ }^{14}$

The aim of this study was to analyze the fibrillin-1 expression by the different (myo)fibroblastic subpopulations of normal and fibrotic rat liver; the expression of fibrillin-1 and of elastin were compared. The role of the profibrogenic mediator transforming growth factor- $\beta 1$ (TGF- $\beta 1$ ) and of mechanical stress on fibrillin-1 expression and modulation was studied in cultures of liver fibroblastic cells. Finally, we also measured the effect of fibrillin-1 fragments on cell adhesion.

\section{Materials and methods}

\section{Experimental Animals}

Male Sprague-Dawley rats (initial body weight about $200 \mathrm{~g}$ ) were used. Four animals were used in each experimental group. In the first group, animals were subjected to common bile duct ligation as described before. ${ }^{3}$ The animals were killed at $72 \mathrm{~h}, 5$ and 7 days after bile duct ligation. In the second group, animals were given carbon tetrachloride $\left(\mathrm{CCl}_{4}\right)$ (375 $\mu \mathrm{l} / \mathrm{kg}$ of body weight in olive oil per os) three times per week. The animals were killed $48 \mathrm{~h}$ after the first $\mathrm{CCl}_{4}$ treatment and at $96 \mathrm{~h}, 2$ and 6 weeks. Control animals were used in each case: sham-operated for the bile duct ligation model, and olive oil per os for the $\mathrm{CCl}_{4}$ model; furthermore, some animals did not undergo any treatment. No differences were observed between all these control groups. All experiments were performed using accepted ethical guidelines.

\section{Processing of Rat Liver Tissue}

A part of fresh tissue samples was routinely formalin-fixed and paraffin-embedded; sections were stained with hematoxylin-eosin for routine histology and with Sirius red (saturated picric acid in distilled water containing $0.1 \%(\mathrm{w} / \mathrm{v})$ Sirius red F3B (BDH Chemicals Ltd., Poole, UK)) to allow visualization of fibrosis. ${ }^{15}$ A part was immediately frozen in liquid nitrogen-cooled isopentane and stored at $-80^{\circ} \mathrm{C}$; five $\mu \mathrm{m}$-thick serial frozen sections of each sample were air-dried on Super frost/plus slides (Menzel Glaser, Germany) and processed for immunostaining.

\section{Cell Culture}

Rat portal fibroblasts were obtained by outgrowth from the biliary tree isolated after collagenase digestion as previously described. ${ }^{9}$ An immortalized rat HSC line (HSC-T6) obtained by transfection of 15-day-old cultured primary HSC with a cDNA in which the expression of the large T-antigen of SV40 is driven by the Rous sarcoma virus promoter ${ }^{16}$ was used; HSC-T6 retain all features of activated hepatic stellate cells, including the expression of desmin, of $\alpha$-smooth muscle actin, and of glial acidic fibrillary protein, and can esterify retinol into retinyl esters. ${ }^{17}$ Human hepatic myofibroblasts were obtained from explants of nontumoral liver resected during partial hepatectomy and characterized as previously described. ${ }^{18,19}$ These human hepatic myofibroblasts were found to express two markers of portal fibroblasts, fibulin-2 and interleukin-6, and not the protease P100, a marker for hepatic stellate cells. ${ }^{20}$ Cells were cultured in Dulbecco's modified Eagle's medium (DMEM, Life Technologies, Cergy Pontoise, France) supplemented with $100 \mathrm{IU} / \mathrm{ml}$ penicillin and $100 \mu \mathrm{g} / \mathrm{ml}$ streptomycin (Life Technologies), at $37^{\circ} \mathrm{C}$ in a humidified atmosphere of $95 \%$ air and $5 \%$ $\mathrm{CO}_{2}$. Rat portal fibroblasts and HSC-T6 were grown in DMEM containing $10 \%$ fetal calf serum (FCS, Life Technologies); human hepatic myofibroblasts were grown in DMEM containing 5\% FCS, 5\% pooled human $\mathrm{AB}$ serum and $5 \mathrm{ng} / \mathrm{ml}$ recombinant human epidermal growth factor (R\&D Systems, Oxon, UK). When cells reached confluence, they were trypsinized and passaged. To study the effect 
of recombinant human TGF- $\beta 1$ (PeproTech, Inc., Rocky Hill, NJ, USA) on fibrillin-1 expression, TGF$\beta 1$ was added $(5 \mathrm{ng} / \mathrm{ml})$ or not on rat or human confluent cells cultured in DMEM containing 1 or $10 \%$ FCS, and immunofluorescence was performed at 3 days after treatment. ${ }^{21}$

\section{Collagen Lattices}

Rat portal fibroblasts or human hepatic myofibroblasts were cultured in collagen lattices. The stock soluble native collagen type I was prepared from rat tails as previously described ${ }^{22}$ and stored at $4^{\circ} \mathrm{C}$ in $0.1 \mathrm{M}$ acetic acid at $3 \mathrm{mg} / \mathrm{ml}$. Fibroblast-populated collagen lattices were manufactured by mixing $1.75 \mathrm{ml}$ of DMEM, $0.5 \mathrm{ml}$ FCS, $1.5 \mathrm{ml}$ collagen solution, $0.25 \mathrm{ml} \mathrm{NaOH} 0.1 \mathrm{~N}$, and $1 \mathrm{ml}$ of DMEM containing $1 \times 10^{6}$ fibroblasts released from monolayer culture by trypsinization. This solution $(5 \mathrm{ml})$ was poured in 60-mm Petri dishes. Dishes were incubated at $37^{\circ} \mathrm{C}$ and a collagen gel with embedded cells formed within $15 \mathrm{~min}$. These dishes either did or did not contain four plastic poles, arranged in a square and glued onto the dish with epoxy glue. Within a floating collagen gel obtained in dishes without plastic poles (unrestrained lattices), the cells slowly contract the gel isotonically, and strain is low; if the gel is anchored to the culture dish with plastic poles (restrained lattices), the cells experience mechanical strain comparable to that observed in contracting skin wounds. ${ }^{23}$ After 2 and 5 days in culture, unrestrained $(n=5)$ and restrained $(n=5)$ fibroblast-populated collagen lattices were immediately frozen in liquid nitrogen-cooled isopentane and stored at $-80^{\circ} \mathrm{C} ; 10 \mu \mathrm{m}$-thick serial frozen sections of each sample were air-dried on Super frost/plus slides (Menzel Glaser) and processed for immunofluorescence.

\section{Adhesion Assay}

Adhesion of human hepatic myofibroblasts to ligand-coated plastic wells for 30-60 min followed by a colorimetric detection of adhering cells was performed according to a previously published protocol. ${ }^{24,25}$ Briefly, 96-well tissue culture plates were coated with serial dilutions (in triplicate) of extracellular matrix substrates $(20-0.31 \mu \mathrm{g} / \mathrm{ml}$, $100 \mu \mathrm{l} /$ well) by overnight adsorption at $4^{\circ} \mathrm{C}$. After saturation of the wells with $1 \%$ bovine serum albumin (BSA, fraction V, Sigma Chemical Company, St Louis, MO, USA), the plates were immediately used for cell adhesion assays in serum-free medium. Cells were added to the wells, and $30 \mathrm{~min}$ after cell seeding, nonadherent and loosely attached cells were removed by aspirating the solution and gentle washing in phosphate-buffered saline. To determine the extent of adhesion, adherent cells were fixed with $1 \%$ glutaraldehyde in phosphatebuffered saline and stained with $0.1 \%$ crystal violet; after extensive washing, the dye was solubilized in Triton X-100, and optical density measured at $750 \mathrm{~nm}$ with an ELISA reader (Labsystems, Vantaa, Finland). Native human fibronectin (gift of $\mathrm{Dr}$ Coussen-Choquet, CNRS UMR 5091, Université Victor Segalen, Bordeaux, France), rat-tail collagen type I, and the recombinant fibrillin-1 polypeptides rF16 (N-terminal half of fibrillin-1) and $\mathrm{rF} 6 \mathrm{H}$ (C-terminal half of fibrillin-1 $)^{26}$ were used.

\section{Antibodies}

For immunohistochemistry and/or immunofluorescence on tissue sections or cultured cells, the following antibodies were used: a polyclonal antiserum produced according to standard procedures in rabbit using the recombinant C-terminal half of human fibrillin-1 $\mathrm{rF} 6 \mathrm{H}$ as antigen $;^{27}$ a monoclonal antibody (IgG2a) recognizing exclusively $\alpha$-smooth muscle actin selected and characterized after immunization of BALB/c mice with the NH2-terminal synthetic decapeptide of $\alpha$-smooth muscle actin coupled to keyhole limpet hemocyanina (Dako A/S, Glostrup, Denmark); ${ }^{28}$ and a rabbit polyclonal antiserum against elastin from rat aorta characterized by radioimmunoassay (Novotec, Lyon, France). ${ }^{29}$ All of these antibodies have been extensively used on rat tissues and their specificity has been clearly documented.

\section{Immunostaining}

For immunohistochemistry, formalin-fixed paraffinembedded sections were incubated with the rabbit polyclonal antibody against fibrillin-1, and treated with the DAKO Envision-horseradish peroxidase system (Dako A/S) as previously described. ${ }^{9}$ For immunofluorescence, frozen sections (tissues and collagen lattices) fixed in cold acetone or cultured cells fixed and permeabilized in cold methanol were incubated with either mouse monoclonal or rabbit polyclonal antibodies. Oregon green 488-conjugated goat anti-mouse IgG (Molecular Probes, Eugene, OR, USA) and Alexa Fluor 594-conjugated goat antirabbit IgG (Molecular Probes) were used for the second step. For double immunofluorescence, mouse monoclonal and rabbit polyclonal antibodies were mixed as well as the second antibodies. In collagen lattices and cultured cells, nuclei were stained with DAPI (Sigma Chemical Company). Frozen sections (tissues and collagen lattices) or cultured cells were mounted in antifade mounting medium. Immunostaining were examined with a Zeiss Axioplan 2 microscope (Carl Zeiss Microscopy, Jena, Germany) equipped with epiillumination and specific filters for immunofluorescence analysis. Images were acquired with an AxioCam camera (Carl Zeiss Vision, Hallbergmoos, Germany) by means of the AxioVision image processing and analysis system (Carl Zeiss Vision). Double stainings 
with green and red fluorescence were artificially treated to evaluate the areas of colocalization (in yellow) using the AxioVision software (Carl Zeiss Vision).

\section{Immunofluorescence Quantitative Evaluation and Statistical Analysis}

Quantitative evaluation of the staining in cultured cells and collagen lattices was performed using a Zeiss Axioplan 2 microscope (Carl Zeiss Microscopy). Images were acquired with an AxioCam camera (Carl Zeiss Vision) by means of the Axiovision image processing and analysis system (Carl Zeiss Vision) and quantitative data of fibrillin-1 staining were obtained using a computerized image analysis system (KS300, Carl Zeiss Vision). The analysis was performed on an average of 20 fields per condition using the $\times 10$ objective. Immunofluorescence staining was expressed as a percentage of stained areas per field. Data were calculated as mean values \pm SEM, and followed a Gaussian distribution. Then, a Student's $t$-test for unpaired samples was used for statistical analysis. A $P<0.05$ was considered significant.

\section{Results}

\section{Hematoxylin-eosin and Sirius Red Staining Examination in Normal and Fibrotic Rat Liver}

In normal liver, Sirius red staining was observed almost exclusively in vessel walls, around centrilobular veins and around bile ducts and vessels in portal connective tissue. At $72 \mathrm{~h}$ after bile duct ligation, bile ductule proliferation was obvious, while very few inflammatory cells were detected in the portal tracts. At this time, fibrous tissue deposition in portal areas was noted as previously described. ${ }^{4}$ At 5 and 7 days after bile duct ligation, bile ductule proliferation progressively penetrated into the parenchyma with a parallel deposition of Sirius red-stained materials. In $\mathrm{CCl}_{4}$-treated animals, a marked inflammatory reaction and hepatocytic necrosis were observed around centrilobular veins at $48 \mathrm{~h}$. Occasionally, bridging necrosis was observed. Histological signs of liver necrosis peaked at $48 \mathrm{~h}$ after a single dose of $\mathrm{CCl}_{4}$. Then, fibrotic lesions developed with a progressive accumulation of Sirius red-stained materials around centrilobular veins leading to the formation of septa.

\section{Fibrillin-1 Expression during Experimental Liver Fibrosis}

In normal rat liver, fibrillin-1 was strongly expressed in the portal connective tissue, in portal vessel walls, around and in the walls of the centrilobular veins (Figure 1a and b); fibrillin-1 expression along the sinusoids was very low (Figure 1a and b). $\alpha$-Smooth muscle actin was expressed exclusively in vessel walls (portal vessels and centrilobular veins) (Figure $1 \mathrm{a}$ and b). Double immunofluorescence showed the close relationship between fibrillin- 1 and $\alpha$-smooth muscle actin in vessel walls (Figure 1a and $b$ ).

After bile duct ligation, we focused our analysis on the portal zones in which the lesion developed. At $72 \mathrm{~h}$ after bile duct ligation (Figure 1c), fibrillin-1 expression was present around proliferating bile ductules where $\alpha$-smooth muscle actin expression increased. After bile duct ligation for 7 days, myofibroblastic cells form dense onion-like layers around biliary structures where fibrillin-1 and $\alpha$ smooth muscle actin appeared colocalized (Figure 1e). Furthermore, fibrillin-1 deposition was also observed around $\alpha$-smooth muscle actin-positive cells invading the parenchyma (Figure 1e).

After $\mathrm{CCl}_{4}$ treatment, the injured centrilobular vein areas were analyzed. At 15 days after the beginning of the $\mathrm{CCl}_{4}$ treatment, the majority of myofibroblastic cells expressing $\alpha$-smooth muscle actin expressed also fibrillin-1 (Figure 1d). After $\mathrm{CCl}_{4}$ treatment for 6 weeks, there was a colocalization of fibrillin- 1 and of $\alpha$-smooth muscle actin in the dense septa which developed between centrilobular vein areas (Figure 1f).

\section{Expression of Elastin by $\alpha$-Smooth Muscle Actin Expressing Myofibroblasts}

After bile duct ligation for 7 days, a patchy elastin deposition was observed in the connective tissue of enlarged portal zones containing $\alpha$-smooth muscle actin-positive myofibroblastic cells; elastin was also present in vessel wall (Figure 2a). In $\mathrm{CCl}_{4}$-treated animals for 6 weeks, a colocalization of elastin and of $\alpha$-smooth muscle actin was observed in fibrous septa (Figure 2b); interestingly, elastin deposition was not observed around $\alpha$-smooth muscle actinpositive stellate cells of the parenchyma (Figure $2 b$, arrows).

\section{Expression and Modulation of Fibrillin-1 in Cultured Hepatic Fibroblastic Cells}

Nontreated cultured rat portal fibroblasts showed a low level of fibrillin-1 expression (Figure 3a). Some extracellular fibrillin-1-containing fibers were observed. Quantitative evaluation (Figure 3c) showed a significantly higher deposition of fibrillin-1 in cells cultured in the presence of $10 \%$ FCS $(10.3 \pm 0.8 \%)$ compared with cells cultured in the presence of $1 \%$ FCS $(5.2 \pm 1.0 \% ; P<0.01)$. Treatment with TGF- $\beta 1$ greatly increased the expression of fibrillin-1 (Figure 3b). Quantitative evaluation (Figure 3c) showed that the increase was significant in cells cultured in the presence of both 1\% FCS $(12.5 \pm 1.3 ; P<0.01$ compared with nontreated cells) and $10 \%$ FCS $(17.8 \pm 0.5 ; P<0.01$ compared with 

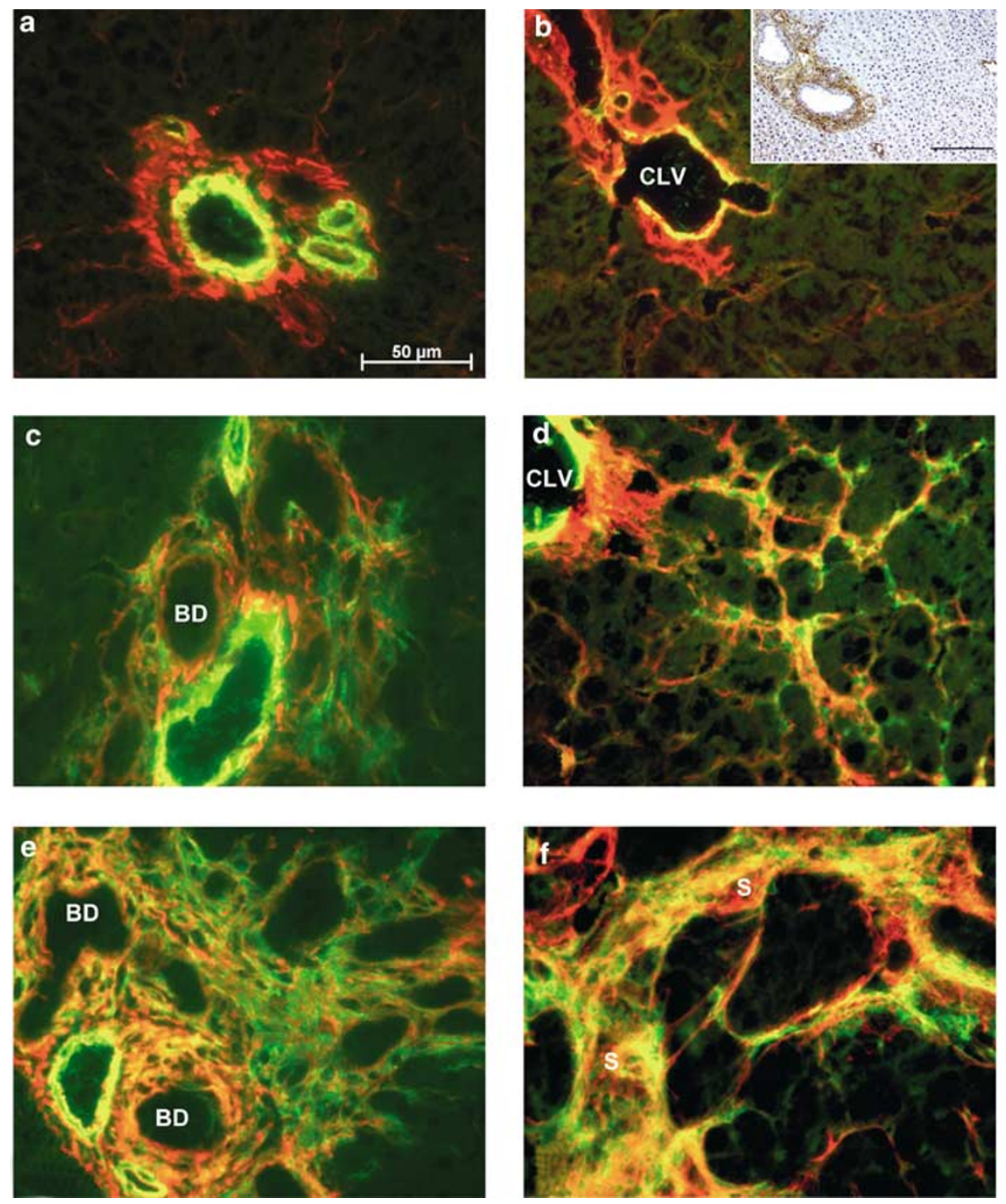

Figure 1 Double immunofluorescence staining for fibrillin-1 (in red) and $\alpha$-smooth muscle actin (in green) in control rat liver (a, b), after

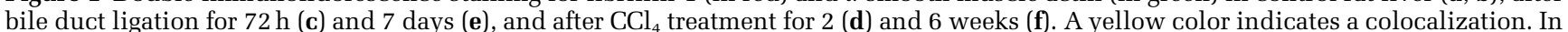
control rats, fibrillin-1 is present in vessel wall where it colocalizes with $\alpha$-smooth muscle actin, and in connective tissue in portal zone (a) and around centrilobular vein (b). A very slight staining for fibrillin-1 is observed in sinusoids (a, b). Inset in (b) illustrates with immunoperoxidase staining the low fibrillin-1 expression level along sinusoids. After bile duct ligation (c, e), fibrillin-1 expression colocalizes with $\alpha$-smooth muscle actin-positive proliferating cells; this deposition is particularly abundant in myofibroblastic layers around bile ductules (BD). After $\mathrm{CCl}_{4}$ treatment (d, f), around centrilobular vein (CLV) and in septa (S), fibrillin-1 expression colocalizes with $\alpha$-smooth muscle actin-positive proliferating cells (b, inset: bar, $200 \mu \mathrm{m}$ ).

non-treated cells). These results were not related to changes in cell numbers since, due to contact inhibition, cell number was identical in all the conditions, as shown by quantitative analysis of the DAPI staining. Similar results were obtained with HSC-T6 and human hepatic myofibroblasts. Quantitative evaluation showed a significantly higher deposition of fibrillin-1 in cells cultured in the presence of $10 \%$ FCS $(5.8 \pm 0.5$ and $14.5 \pm 0.3 \%$ in HSC-T6 and human hepatic myofibroblasts, respectively) compared with cells cultured in the presence of $1 \%$ FCS $(3.2 \pm 0.3$ and $9.6 \pm 0.7 \%$ in HSC-T6 and human hepatic myofibroblasts, respectively; $P<0.02$ ). Treatment with TGF- $\beta 1$ significantly increased the expression of fibrillin-1 in cells cultured in the presence of both $1 \%$ FCS $(7.5 \pm 1.0$ and $17.8 \pm 0.7$ in HSC-T6 and human hepatic myofibroblasts, respectively; $P<0.01$ compared with nontreated cells) and $10 \%$ FCS $(12.7 \pm 0.5$ and $21.4 \pm 1.2$ in HSC-T6 and human hepatic myofibroblasts, respectively; $P<0.01$ compared with nontreated cells).

To detect modifications of fibrillin-1 expression that may be induced under conditions of mechanical stress, we analyzed cells (rat portal fibroblasts and human hepatic myofibroblasts) cultured in restrained vs unrestrained collagen gels. Indeed, fibroblasts cultured within collagen lattices exert 

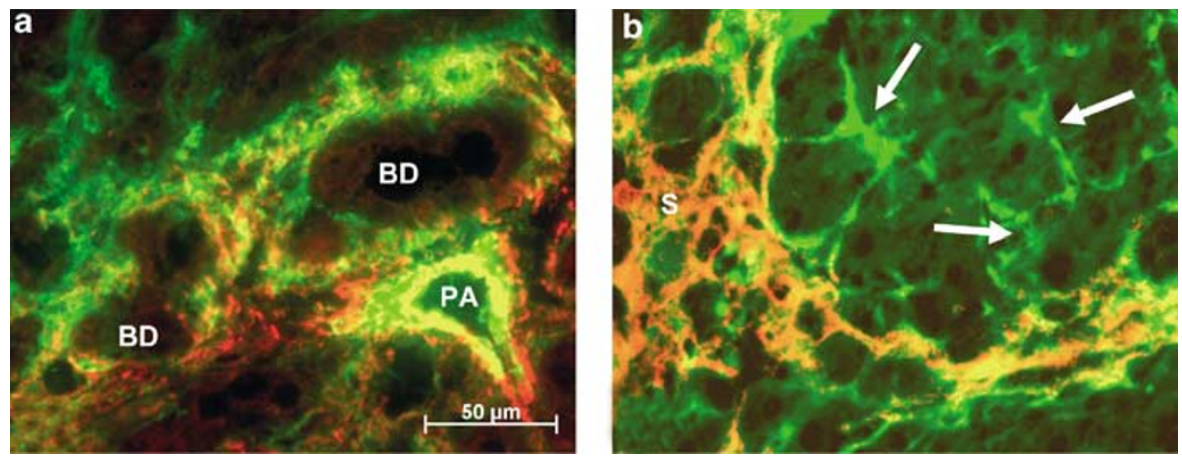

Figure 2 Double immunofluorescence staining for elastin (in red) and $\alpha$-smooth muscle actin (in green) after bile duct ligation for 7 days (a) or after $\mathrm{CCl}_{4}$ treatment for 6 weeks (b). A yellow color indicates a colocalization. In both model (a, b), elastin and $\alpha$-smooth muscle

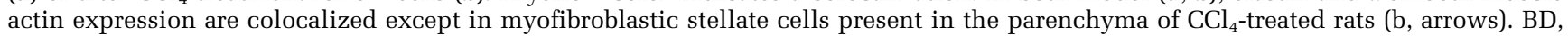
bile ductule; PA, portal artery; S, septa.

tractional forces leading to the retraction of unrestrained, floating collagen lattices and to the development of tension in attached, restrained (stressed) collagen lattices. ${ }^{30}$ At the beginning of the culture, the collagen matrix covered the entire dish. Within 2 days, the fibroblasts in the unrestrained collagen gels contracted the matrix to a small disc. In collagen gels restrained with plastic poles, the partially contracted gel had the shape of a stretched rubber sheet. Between 2 and 5 days in culture, a significant increase of the fibrillin-1 expression was observed in both unrestrained and restrained fibroblast-populated collagen lattices (Table 1). However, at both times, the level of expression was significantly higher in restrained (stressed) fibroblast-populated collagen lattices compared with unrestrained fibroblast-populated collagen lattices (Table 1).

Adhesion assays were performed with human hepatic myofibroblasts using a range of concentrations of extracellular matrix proteins (0.31-20 $\mu \mathrm{g} / \mathrm{ml})$. Cell adhesion on collagen type I was already maximal at the lowest concentration tested (Figure 4a). At $0.31 \mu \mathrm{g} / \mathrm{ml}$, the adhesion capacities of the cells on fibronectin, $\mathrm{rF} 6 \mathrm{H}$ (C-terminal half containing a cell binding RGD motif) and rF16 (Nterminal half) recombinant fibrillin-1 fragments were equivalent (Figure 4a). When concentration increased, cell adhesion on fibronectin increased to reach a plateau at $2.5 \mu \mathrm{g} / \mathrm{ml}$, adhesion on $\mathrm{rF} 6 \mathrm{H}$ fibrillin-1 fragment slightly increased then decreased at concentrations higher than $2.5 \mu \mathrm{g} / \mathrm{ml}$, while adhesion on rF16 fibrillin-1 fragment was dose-dependently inhibited (Figure 4a). The effects of fibrillin-1 fragments on collagen type I and fibronectin-induced cell adhesion were then studied. The concentrations of collagen type I and of fibronectin chosen were 0.31 and $2.5 \mu \mathrm{g} / \mathrm{ml}$, respectively. The presence of fibrillin-1 fragments did not significantly modify adhesion of the cells to collagen type I (Figure 4b). On fibronectin, the rF6 H fragment of fibrillin-1 did not significantly modify cell adhesion on fibronectin while the rF16 fragment decreased cell adhesion from $2.5 \mu \mathrm{g} / \mathrm{ml}$ (87\% adhesion compared to fibronectin alone) to inhibit almost totally cell adhesion on fibronectin at $10 \mu \mathrm{g} / \mathrm{ml}(13 \%$ adhesion compared to fibronectin alone; Figure 4c). Figure $4 \mathrm{~d}$ and e illustrates the reduced adhesion and spreading of cells on fibronectin in the presence of rF16 fibrillin-1 fragment.

\section{Discussion}

In this work, we showed that, in normal rat liver, fibrillin-1 is present in portal and peri-centrilobular vein connective tissue. Furthermore, we showed that fibrillin-1 is an important component of the extracellular matrix secreted during experimental rat liver fibrosis. In contrast with human liver, ${ }^{10}$ fibrillin-1 expression inside the sinusoids of rat liver was either absent or very low. After bile duct ligation or $\mathrm{CCl}_{4}$ treatment, fibrillin-1 expression increased greatly in enlarged portal zones or in pericentrilobular vein areas, respectively.

In normal rat liver, fibrillin-1, and $\alpha$-smooth muscle actin were colocalized exclusively in vessel walls. After bile duct ligation and $\mathrm{CCl}_{4}$ treatment, fibrillin- 1 and $\alpha$-smooth muscle actin were colocalized in fibrotic lesions. This suggests that $\alpha$-smooth muscle actin-positive myofibroblasts are responsible for the deposition of extracellular fibrillin-1 observed during fibrogenesis. Elastin and $\alpha$-smooth muscle actin were colocalized in portal areas after bile duct ligation and in septa developing after $\mathrm{CCl}_{4}$ treatment, but a few activated $\alpha$-smooth muscle actin-positive HSC in the parenchyma did not express elastin. These observations suggest that different fibroblastic subpopulations of the liver, including HSC and portal fibroblasts, are involved in fibrillin-1 deposition. However, in the $\mathrm{CCl}_{4}$ model and at the times studied, typical activated HSC expressing $\alpha$-smooth muscle actin and secreting fibrillin-1 are not or are poorly involved in elastin deposition. It has been shown recently that HSC secrete the soluble tropoelastin and that its secretion 

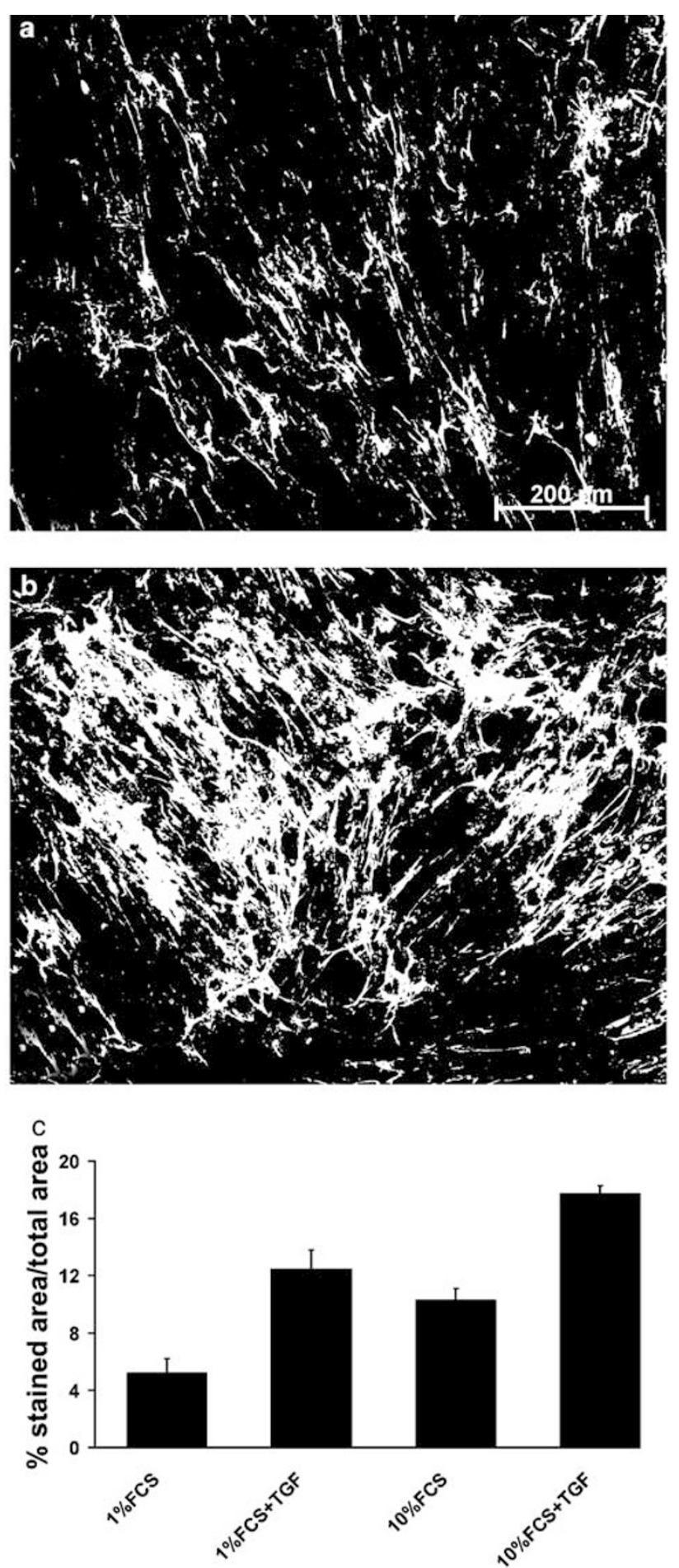

Figure 3 Fibrillin-1 (a, b) immunofluorescence staining of nontreated (a) and TGF- $\beta 1$-treated (b) portal fibroblasts in the presence of 1\% FCS. Fibrillin-1 expression is increased by TGF$\beta 1$ treatment. Fibrillin-1 immunostaining quantitative analysis (c) shows a significant increase in fibrillin-1 expression in cells cultured in 10\% FCS compared with cells cultured with 1\% FCS, and in TGF- $\beta 1$-treated cells compared with nontreated cells.

increases during transdifferentiation to myofibroblast-like cells both in vitro and in vivo, ${ }^{31}$ but, according to our observations, immunohistochemistry revealed elastin only in the septa.
Table 1 Quantitative evaluation of fibrillin-1 expression in unrestrained and restrained fibroblast-populated collagen

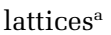

\begin{tabular}{lcccc}
\hline $\begin{array}{l}\text { Time in } \\
\text { culture }\end{array}$ & \multicolumn{2}{c}{ Rat portal fibroblasts } & \multicolumn{2}{c}{$\begin{array}{c}\text { Human hepatic } \\
\text { myofibroblasts }\end{array}$} \\
\cline { 2 - 5 } & $\begin{array}{c}\text { Unrestrained } \\
\text { collagen } \\
\text { lattices }\end{array}$ & $\begin{array}{c}\text { Restrained } \\
\text { collagen } \\
\text { lattices }\end{array}$ & $\begin{array}{c}\text { Unrestrained } \\
\text { collagen } \\
\text { lattices }\end{array}$ & $\begin{array}{c}\text { Restrained } \\
\text { collagen } \\
\text { lattices }\end{array}$ \\
\hline 2 days & $5.3 \pm 0.6$ & $7.5 \pm 0.5$ & $8.8 \pm 1.0$ & $13.4 \pm 0.9$ \\
5 days & $9.7 \pm 0.3$ & $12.3 \pm 1.1$ & $11.9 \pm 0.9$ & $15.8 \pm 0.7$ \\
\hline
\end{tabular}

ammunofluorescence staining was quantified at the microscopic level and expressed as a percentage of stained areas per field. Significant differences were observed in fibroblastic cells cultured for 5 days compared with fibroblastic cells cultured for 2 days $(P<0.02$ for both rat and human fibroblasts), and in restrained collagen lattices compared with unrestrained collagen lattices $(P<0.03$ at 2 days for both rat and human fibroblasts; $P<0.01$ at 5 days for both rat and human fibroblasts). Quantitative evaluation was performed in areas in the gels where cell density as evaluated by the DAPI staining was homogeneous $(n=5)$.

Our in vitro experiments showed that rat HSC (HSC-T6), rat portal fibroblasts, and human liver myofibroblasts express fibrillin- 1 and that TGF- $\beta 1$ increases fibrillin-1 expression. These results are not unexpected since TGF- $\beta 1$ plays a major role in liver fibrogenesis and extracellular matrix deposition. ${ }^{32,33}$ An overexpression of TGF- $\beta 1$ has been reported in the two models of fibrogenesis that we have used ${ }^{34,35}$ and could thus account for the increased expression of fibrillin-1. TGF- $\beta$ activity requires the proteolytic cleavage of the latent TGF- $\beta$ binding protein (LTBP) that releases the latent TGF$\beta$ complex, subsequently dissociated yielding the mature TGF- $\beta$ (for review, see Saharinen ${ }^{36}$ ). It has been shown that LTBP interacts with fibrillin and is a microfibril-associated protein. ${ }^{37}$ It is thus possible that fibrillin-1 interferes with TGF- $\beta$ bioavailability as recently discussed..$^{38}$

Fibrillin-1 expression was increased in restrained fibroblast-populated collagen lattices compared with unrestrained fibroblast-populated lattices. The unrestrained fibroblast-populated floating lattices give rise to mechanically relaxed tissue resembling the normal uninjured tissue in which cells develop stellate morphology with long processes. ${ }^{39}$ In contrast, restrained fibroblast-populated collagen-anchored lattices resemble that of a stressed tissue, such as granulation tissue, ${ }^{39}$ in which the cells are bipolar and orient along lines of tension. Our results thus illustrate the likely involvement of fibrillin-1 in the mechanical properties of a tissue, fibrillin-1 providing force-bearing structural support as suggested by Ramirez and Pereira. ${ }^{40}$

Ultrastructural and biochemical studies have shown a direct interaction between fibrillin-1 and the cell surface mediated via a RGD motif and the integrin $\alpha \mathrm{V} \beta 3 .^{12,13}$ Thus, fibrillin may act as a classical adhesion protein. ${ }^{12,13,41,42}$ However, our 

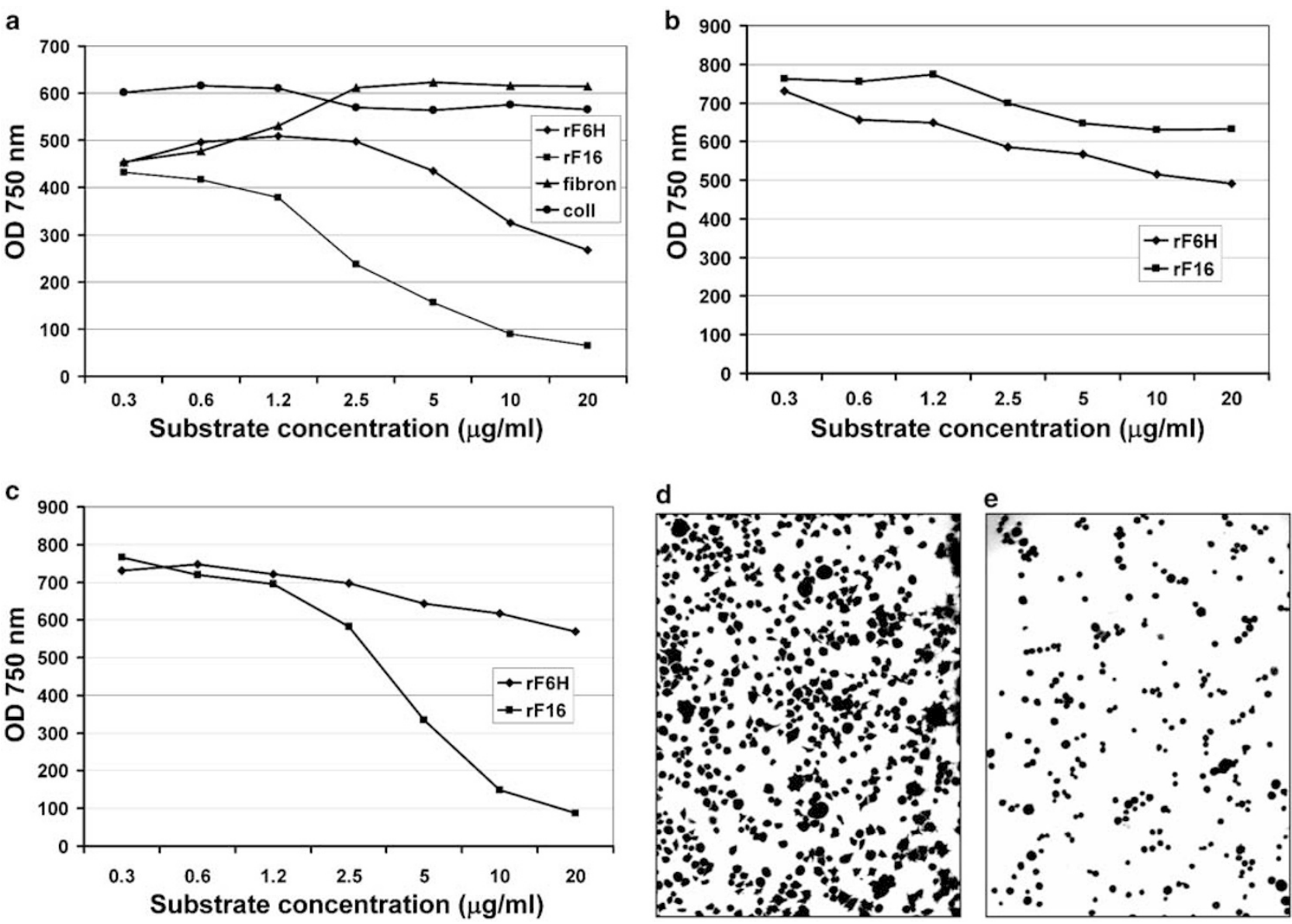

Figure 4 Adhesion tests. In (a), adhesion of myofibroblasts on increasing amounts of collagen type I, fibronectin, and $\mathrm{rF6H}$ or $\mathrm{rF} 16$ fibrillin-1 fragments is tested; cell adhesion on collagen type I is already maximal at the lowest concentration tested. At $0.31 \mu \mathrm{g} / \mathrm{ml}$, the adhesion capacities of the cells on fibronectin, $\mathrm{rF} 6 \mathrm{H}$ and $\mathrm{rF} 16$ recombinant fibrillin-1 fragments are equivalent. When concentration increases, cell adhesion on fibronectin increases, adhesion on $\mathrm{rF} 6 \mathrm{H}$ fibrillin-1 fragment slightly increases then decreases, while adhesion on rF16 fibrillin-1 fragment is dose-dependently inhibited. In (b), cell adhesion on collagen type I is not significantly modified by the addition of fibrillin-1 fragments; in contrast, cell adhesion on fibronectin is decreased by the rF16 fibrillin-1 fragment (c). Each point represents the average of triplicate wells. SEMs are not represented in figures but were always lower than $2 \%$ of values. (d) and (e) illustrate cell adhering on fibronectin $(2.5 \mu \mathrm{g} / \mathrm{ml})$ alone (d) or in the presence of $5 \mu \mathrm{g} / \mathrm{ml} \mathrm{rF} 16$ fragment (50\% adhesion compared to fibronectin alone) (e). Cells were stained with $0.1 \%$ crystal violet $30 \mathrm{~min}$ after seeding.

results on human myofibroblasts which express $\alpha \mathrm{V} \beta 3$ (FACS analysis; A Desmoulière, unpublished observation) demonstrate that recombinant human fibrillin-1 polypeptides, far from being proadhesive, are actually antiadhesive, albeit with distinctive features. Whereas the recombinant human fibrillin-1 polypeptide $\mathrm{rF} 6 \mathrm{H}$ containing the RGD fragment (Cterminal half of fibrillin-1) slightly decreases cell adhesion at high concentrations, its addition does not modify cell adhesion on collagen type I or fibronectin. In contrast, the recombinant human fibrillin-1 polypeptide rF16 (N-terminal half of fibrillin-1) dose-dependently decreases cell adhesion and inhibits cell adhesion on fibronectin, although not on collagen type I. Fibrillin-1 can be cleaved into specific peptides by different matrix metalloproteinases (MMP) including gelatinases MMP-2 and -9, the macrophage metalloelastase MMP-12, the interstitial collagenase MMP-13, the membrane-type MMP-14 (also known as
MT-MMP1), ${ }^{43,44}$ and the stromelysin MMP-3. ${ }^{43}$ Thus, it is likely that MMP activity in physiologically and pathologically remodeling connective tissues is able to generate fibrillin-1 fragments displaying different adhesive properties. Owing to their antiadhesive properties, fibrillin-1 fragments could facilitate cell mobilization to the site of injury. In this aspect, fibrillin-1 fragments share similarities to matricelullar proteins (tenascins, thrombospondins, and SPARC) that function as adaptators and modulators of cell-matrix interactions. ${ }^{45,46}$

In conclusion, our results show that different (myo)fibroblastic cell subpopulations of the liver synthesize fibrillin- 1 and that TGF- $\beta 1$ induces fibrillin-1 deposition. Furthermore, fibrillin-1 deposition was induced in vitro by mechanical stress. Finally, a recombinant human fibrillin-1 fragment was shown to display antiadhesive properties, suggesting that, during connective tissue remodeling involving proteases, fibrillin-1 fragment 
can act differently as compared to the intact molecule.

\section{Acknowledgement}

We are very grateful to Dr Friedman (Department of Medicine, Division of Liver Diseases, Mount Sinai School of Medicine, New York, USA) for HSC-T6 cells. We thank Dr Aumailley (Institute for Biochemistry II, Medical Faculty, University of Cologne, Germany) for helpful discussion concerning cell adhesion and Dr Pitard (CNRS UMR 5540, Bordeaux 2 University, France) for FACS analysis. This work was supported in part by the Région Aquitaine, and a visiting fellowship awarded to Ian A Darby by the University of Bordeaux 2. DL was recipient of a fellowship from CAPES (Brazil).

\section{References}

1 Gressner AM, Bachem MG. Molecular mechanisms of liver fibrogenesis - a homage to the role of activated fat-storing cells. Digestion 1995;56:335-346.

2 Pinzani M, Gentilini P. Biology of hepatic stellate cells and their possible relevance in the pathogenesis of portal hypertension in cirrhosis. Semin Liver Dis 1999;19:397-410.

3 Tuchweber B, Desmoulière A, Bochaton-Piallat ML, et al. Proliferation and phenotypic modulation of portal fibroblasts in the early stages of cholestatic fibrosis in the rat. Lab Invest 1996;74:265-278.

4 Desmoulière A, Darby I, Costa AM, et al. Extracellular matrix deposition, lysyl oxidase expression, and myofibroblastic differentiation during the initial stages of cholestatic fibrosis in the rat. Lab Invest 1997;76:765-778.

5 Kinnman N, Francoz C, Barbu V, et al. The myofibroblastic conversion of peribiliary fibrogenic cells distinct from hepatic stellate cells is stimulated by platelet-derived growth factor during liver fibrogenesis. Lab Invest 2003;83:163-173.

6 Knittel T, Kobold D, Piscaglia F, et al. Localization of liver myofibroblasts and hepatic stellate cells in normal and diseased rat livers: distinct roles of (myo-)fibroblast subpopulations in hepatic tissue repair. Histochem Cell Biol 1999;112:387-401.

7 Knittel T, Kobold D, Saile B, et al. Rat liver myofibroblasts and hepatic stellate cells: different cell populations of the fibroblast lineage with fibrogenic potential. Gastroenterology 1999;117:1205-1221.

8 Cassiman D, Libbrecht L, Desmet V, et al. Hepatic stellate cell/myofibroblast subpopulations in fibrotic human and rat livers. J Hepatol 2002;36:200-209.

9 Uchio K, Tuchweber B, Manabe $\mathrm{N}$, et al. Cellular retinol-binding protein-1 expression and modulation during in vivo and in vitro myofibroblastic differentiation of rat hepatic stellate cells and portal fibroblasts. Lab Invest 2002;82:619-628.

10 Dubuisson L, Lepreux S, Bioulac-Sage $\mathrm{P}$, et al. Expression and cellular localization of fibrillin-1 in normal and pathological human liver. J Hepatol 2001;34:514-522.
11 Lamireau T, Dubuisson L, Lepreux S, et al. Abnormal hepatic expression of fibrillin-1 in children with cholestasis. Am J Surg Pathol 2002;26:637-646.

12 Pfaff M, Reinhardt DP, Sakai LY, et al. Cell adhesion and integrin binding to recombinant human fibrillin-1. FEBS Lett 1996;384:247-250.

13 Sakamoto H, Broekelmann T, Cheresh DA, et al. Celltype specific recognition of RGD- and non-RGDcontaining cell binding domains in fibrillin-1. J Biol Chem 1996;271:4916-4922.

14 Kielty CM, Baldock C, Lee D, et al. Fibrillin: from microfibril assembly to biomechanical function. Philos Trans R Soc Lond B Biol Sci 2002;357:207-217.

15 Manabe N, Chevallier M, Chossegros P, et al. Interferon-alpha $2 b$ therapy reduces liver fibrosis in chronic non-A, non-B hepatitis: a quantitative histological evaluation. Hepatology 1993;18:1344-1349.

16 Vogel S, Piantedosi R, Frank J, et al. An immortalized rat liver stellate cell line (HSC-T6): a new cell model for the study of retinoid metabolism in vitro. J Lipid Res 2000;41:882-893.

17 Kim Y, Ratziu V, Choi SG, et al. Transcriptional activation of transforming growth factor beta1 and its receptors by the Kruppel-like factor Zf9/core promoterbinding protein and Sp1. Potential mechanisms for autocrine fibrogenesis in response to injury. J Biol Chem 1998;273:33750-33758.

18 Win KM, Charlotte F, Mallat A, et al. Mitogenic effect of transforming growth factor-beta 1 on human Ito cells in culture: evidence for mediation by endogenous platelet-derived growth factor. Hepatology 1993;18:137-145.

19 Blazejewski S, Préaux AM, Mallat A, et al. Human myofibroblastlike cells obtained by outgrowth are representative of the fibrogenic cells in the liver. Hepatology 1995;22:788-797.

20 Davaille J, Gallois C, Habib A, et al. Antiproliferative properties of sphingosine 1-phosphate in human hepatic myofibroblasts. A cyclooxygenase- 2 mediated pathway. J Biol Chem 2000;275:34628-34633.

21 Desmoulière A, Geinoz A, Gabbiani F, et al. Transforming growth factor- $\beta 1$ induces $\alpha$-smooth muscle actin expression in granulation tissue myofibroblasts and in quiescent and growing cultured fibroblasts. J Cell Biol 1993;122:103-111.

22 Ehrlich HP, Rajaratnam JB. Cell locomotion forces versus cell contraction forces for collagen lattice contraction: an in vitro model of wound contraction. Tissue Cell 1990;22:407-417.

23 Delvoye P, Wiliquet P, Leveque JL, et al. Measurement of mechanical forces generated by skin fibroblasts embedded in a three-dimensional collagen gel. J Invest Dermatol 1991;97:898-902.

24 Aumailley M, Mann K, von der Mark $\mathrm{H}$, et al. Cell attachment properties of collagen type VI and Arg-Gly-Asp dependent binding to its alpha 2(VI) and alpha 3(VI) chains. Exp Cell Res 1989;181: 463-474.

25 Dogic D, Rousselle P, Aumailley M. Cell adhesion to laminin 1 or 5 induces isoform-specific clustering of integrins and other focal adhesion components. J Cell Sci 1998;111:793-802.

26 Jensen SA, Reinhardt DP, Gibson MA, et al. Protein interaction studies of MAGP-1 with tropoelastin and fibrillin-1. J Biol Chem 2001;276:39661-39666.

27 Tiedemann K, Batge B, Muller PK, et al. Interactions of fibrillin-1 with heparin/heparan sulfate, implications 
for microfibrillar assembly. J Biol Chem 2001;276: 36035-36042.

28 Skalli O, Ropraz P, Trzeciak A, et al. A monoclonal antibody against alpha-smooth muscle actin: a new probe for smooth muscle differentiation. J Cell Biol 1986;103:2787-2796.

29 Lethias C, Hartmann DJ, Masmejean M, et al. Ultrastructural immunolocalization of elastic fibers in rat blood vessels using the protein A-gold technique. J Histochem Cytochem 1987;35:15-21.

30 Chiquet-Ehrismann R, Tannheimer M, Koch M, et al. Tenascin-C expression by fibroblasts is elevated in stressed collagen gels. J Cell Biol 1994;127:2093-2101.

31 Kanta J, Dooley S, Delvoux B, et al. Tropoelastin expression is up-regulated during activation of hepatic stellate cells and in the livers of $\mathrm{CCl}(4)$-cirrhotic rats. Liver 2002;22:220-227.

32 Bedossa $\mathrm{P}$, Peltier E, Terris $\mathrm{B}$, et al. Transforming growth factor-beta 1 (TGF-beta 1) and TGF-beta 1 receptors in normal, cirrhotic, and neoplastic human livers. Hepatology 1995;21:760-766.

33 Gressner AM, Weiskirchen R, Breitkopf $\mathrm{K}$, et al. Roles of TGF-beta in hepatic fibrosis. Front Biosci 2002;7:d793-d807.

34 Armendariz-Borunda J, Seyer JM, Kang AH, et al. Regulation of TGF beta gene expression in rat liver intoxicated with carbon tetrachloride. FASEB J 1990;4:215-221.

35 Saperstein LA, Jirtle RL, Farouk M, et al. Transforming growth factor-beta 1 and mannose 6-phosphate/insulin-like growth factor-II receptor expression during intrahepatic bile duct hyperplasia and biliary fibrosis in the rat. Hepatology 1994;19:412-417.

36 Saharinen J, Hyytiainen M, Taipale J, et al. Latent transforming growth factor-beta binding proteins
(LTBPs) - structural extracellular matrix proteins for targeting TGF-beta action. Cytokine Growth Factor Rev 1999;10:99-117.

37 Isogai Z, Ono RN, Ushiro S, et al. Latent transforming growth factor beta-binding protein 1 interacts with fibrillin and is a microfibril-associated protein. J Biol Chem 2003;278:2750-2757.

38 Kaartinen V, Warburton D. Fibrillin controls TGF-beta activation. Nat Genet 2003;33:331-332.

39 Grinnell F. Fibroblasts, myofibroblasts, and wound contraction. J Cell Biol 1994;124:401-404.

40 Ramirez F, Pereira L. The fibrillins. Int J Biochem Cell Biol 1999;31:255-259.

41 Kielty CM, Whittaker SP, Grant ME, et al. Attachment of human vascular smooth muscles cells to intact microfibrillar assemblies of collagen VI and fibrillin. J Cell Sci 1992;103:445-451.

42 D'Arrigo C, Burl S, Withers AP, et al. TGF-beta1 binding protein-like modules of fibrillin-1 and -2 mediate integrin-dependent cell adhesion. Connect Tissue Res 1998;37:29-51.

43 Ashworth JL, Murphy G, Rock MJ, et al. Fibrillin degradation by matrix metalloproteinases: implications for connective tissue remodelling. Biochem J 1999;340:171-181.

44 Hindson VJ, Ashworth JL, Rock MJ, et al. Fibrillin degradation by matrix metalloproteinases: identification of amino- and carboxy-terminal cleavage sites. FEBS Lett 1999;452:195-198.

45 Murphy-Ullrich JE. The de-adhesive activity of matricellular proteins: is intermediate cell adhesion an adaptive state? J Clin Invest 2001;107:785-790.

46 Sage EH. Regulation of interactions between cells and extracellular matrix: a command performance on several stages. J Clin Invest 2001;107:781-783. 